\title{
Investigation of the relationship between atherosclerosis and interleukin-6 -174G / C gene polymorphism
}

\author{
Umut Serhat Sanri॰
}

Department of Cardiovascular Surgery, University of Health Sciences, Bursa Yüksek İhtisas Training and Research Hospital, Bursa, Turkey

\section{ABSTRACT}

Objectives: Atherosclerosis is a chronic disease that causes various cardiovascular complications. The onset and progression of atherosclerosis depends primarily on genetic factors and life style, but the underlying cellular and molecular mechanisms are still unclear. In recent studies, circulating cytokines have been shown to play an important role in inflammatory events. Interleukin-6 (IL-6) plays an important role in the regulation of proinflammation. In this study, a single nucleotide polymorphism of IL-6 gene at position -174 was studied. Our aim was to investigate the relationship between IL-6 -174G/C polymorphism and atherosclerosis.

Methods: In this prospective randomized study, 104 patients were included in both groups. We used Polymerase Chain Reaction-Restriction Fragment Lenght Polymorphism (PCR-RFLP) method to amplify the polymorphism region.

Results: Allele frequency distributions of IL-6 -174G/C polymorphism in the study and control groups were evaluated. There were no statistically significant diversity between $\mathrm{A}$ and $\mathrm{B}$ allele frequencies.

Conclusions: The allele frequency and genotype distribution between the groups was not statistically different, which indicates another mechanisms on regulation of these cytokines. Single gene polymorphisms are generally not reproducible. Therefore, broad-based studies should be carried out considering suitable conditions and multi-factor features.

Keywords: Coronary atherosclerosis, IL-6 gene polymorphism, risk factors

A therosclerotic coronary artery disease is the leading cause of cardiovascular morbidity and mortality in developed countries. Risk factors such as presence of family history, lipid disorders, diabetes mellitus, metabolic syndrome, obesity, hypertension, sedentary life, smoking, hyperhomocysteinemia and increased CRP level were determined [1-3].

Many risk factors have been mentioned in the pathogenesis of atherosclerosis and genetic studies have gained importance [4]. Proinflammatory and anti-inflammatory types of cytokines have been demonstrated that contribute to the pathogenesis of many infections, inflammations, autoimmune and malignant diseases. Genes affecting the structures which involved in the inflammatory process have been demonstrated to contribute directly and indirectly to the development of atherosclerosis [5].

Cytokines take an important role in the control and regulation of response versus external antigens and agents, and also play an important role in local and systemic inflammatory response by regulating intercellular relationships. A significant part of the 
cytokines secreted from the immune system are interleukins and their primary task is to stimulate immune system cells. Interleukin-6 (IL-6), which has an important role on cytotoxic T cells, is also involved in a system regulated by these genes [6].

IL-6 is an interleukin that synthesized by IL-1 stimulation by mononuclear phagocytic cells (MFH), endothelial cells, fibroblasts, monocytes, keratinocytes, mesangial cells and bone marrow stromal cells. IL-6 mainly involves in regulation of immune and inflammatory response, hematopoietic system and central nervous system [7]. IL-6, as a pleiotropic cytokine, induces $\mathrm{T}$ and $\mathrm{B}$ cell differentiation and proliferation and also induces vascular endothelial growth factor production [7]. IL-6 facilitates the adhesion of endothelial cells to lymphocytes by increasing the expression of E-selectin molecules, intercellular adhesion molecule-1 (ICAM-1) and vascular cell adhesion molecule-1 (VCAM-1) in endothelial cells. [7].

The IL-6 gene is located in the chromosome '7p21-14'. To date, two major functional single gene nucleotide polymorphisms have been identified in the IL-6 gene region, namely $-572 \mathrm{G} / \mathrm{C}$ and $-174 \mathrm{G} / \mathrm{C}$. This gene polymorphism may be effective in many inflammatory events including vascular pathologies by affecting plasma IL-6 and C-reactive protein (CRP) levels [8-10].

It has been declared that $174 \mathrm{G} / \mathrm{C}$ polymorphism may be associated with atherosclerosis and coronary artery disease [11]. The aim of this study is to investigate the relationship between IL-6 -174G/C gene polymorphism, which is responsible for the regulation of the functions of IL-6 and coronary artery atherosclerosis and to contribute to the elucidation of etiologic factors.

\section{METHODS}

\section{The Patients}

In this prospective randomized study, patients were selected from patients who underwent coronary angiography with a preliminary diagnosis of coronary artery disease. In this study 104 patients with a decision of coronary bypass surgery were included as the study group (Group 1) and 104 patients with normal coronary flow were included as the control group (Group 2). The study was approved by the local institutional Ethical Committee of Cumhuriyet University (Ethical Committee number: 2011-109).

Patients with preoperative cerebrovascular disease, presence of valvular heart disease, peripheral arterial disease, renal insufficiency were not included in the study. All data were recorded as age, gender, history of hypertension, diabetes mellitus, smoking.

\section{Blood Sampling and Biochemical Analyses DNA isolation}

Fasting blood samples were taken from antecubital vein of patients who included study. The tubes with EDTA were used for automatic blood count according to the protocol of our hospital.

Total genomic DNA isolation from individuals was performed by making some modifications in the standard phenol-chloroform protocol described by Sambrook et al. [12].

\section{Agarose Gel Electrophoresis}

Approximately $5 \mu 1$ of the amplification product was taken and mixed with $1 \mu 1$ loading buffer $(50 \%$ glycerol, $0.1 \mathrm{M}$ EDTA, 0.1\% bromophenol blue, Xylene cyano). $1.5 \%$ agarose gel was separated in Tris-Boric acid-EDTA (TBE) buffer (0.089 M Tris, $0.089 \mathrm{M}$ Boric Acid and 0.011 M EDTA, pH: 8.3).In the preparation of agarose gel, 10X TBE, distilled water, $0.5 \mu \mathrm{g} / \mathrm{ml}$ ethidium bromide and agarose (sigma) were used. After electrophoresis, DNA was visualized under ultraviolet light and Polymerase chain reaction $(\mathrm{PCR})$ products were checked.

\section{PCR Amplification}

The region with 431 base pairs which containing the polymorphism region was amplified by polymerase chain reaction (PCR) using primers 5'CAGAAGAACTCAGATGACTG3 'and 5'GTGGGGCTGATTGGAAACC3.The PCR products which obtained were exposed to $2 \%$ agarose gel electrophoresis and the emerged bands were stained with ethidium bromide and imaged under UV.

\section{Length Variability Reaction of Restriction Section (LVRS)}

In the polymorphism studied in IL-6, genotypes of the individuals were determined by PCR based Length 
Variability Reaction of Restriction Section (LVRS) method. Restriction cutting conditions using the enzyme for polymorphism are as follows.

Restriction of digestion:

- Distilled water: $3.5 \mu \mathrm{l}$

- Enzyme buffer: $1 \mu 1$

- Restriction Enzyme: $0.5 \mu 1$

- PCR product: $5 \mu 1$

- Total volume: 10

NlaIII restriction enzyme was used to determine the IL-6 locus and Codon -174G > C polymorphism. Enzyme buffer (Tris-acetate pH: 7.9, $10 \mathrm{mM}$ magnesium acetate, $66 \mathrm{mM}$ potassium acetate, $0.1 \mathrm{mg}$ / ml BSA, Fermentas) was used at a 10-fold concentration.

Amplification of the primer pair used in the detection of the IL- 6 gene codon $-174 \mathrm{G}>\mathrm{C}$ mutation revealed the fragment sizes as follows; GG: 233,202,176,29 bp GC: 233,202,111,122,176,29 CC: 202,111,122,176,29 (total size 640 base pairs).

\section{Sequence Analysis}

In order to confirm the genotypes determined by LVRS method, $5 \%$ of the samples belonging to individuals with different genotypes (wild, heterozygous and variant genotype) were subjected to sequence analysis. By means of sequence analysis, the risk of partial digestion resulting from LVRS was eliminated. In this study, PCR products were purified from gel using DNA extraction kit (AXYGEN). PCR products of different genotype were run on $1 \%$ agarose gel. The bands of each sample in the gel were cut with a scalpel under UV and cut into small pieces on a clean surface and placed in $1.5 \mathrm{ml}$ Eppendorf tubes. Each tube was tared on a precision scale and the weights of the gel pieces were measured. AXYGEN's DNA gel extraction Spin Protocol was used for DNA Isolation from the gel. The gel piece containing the PCR band was placed in the tube. Buffer DE-A (Gel solvent) was added to the gel pieces in each tube 3 times of each volume. Each tube was vortexed until suspended. Each tube was heated to $75{ }^{\circ} \mathrm{C}$ for $6-8$ minutes to completely dissolve the gel. The tube was vortexed gently every 2-3 minutes and the dissolution of the gel was accelerated. Buffer DE-B (Binding Buffer) was added in as much as the half volume of Buffer DE-A used in the process. An equal amount of isopropanol was added to the sample volume. The filtration column was placed in Eppendorf tubes and centrifuged at $15000 \mathrm{rpm}$ for $1 \mathrm{~min}$. The filtration column was removed and the liquid descending to the bottom of the tube was pipetted. Then the filtration column was placed again and $500 \mu 1$ of Buffer W1 (Wash Buffer) was added. It was centrifuged for 30 $\mathrm{sec}$ at 15,000 rpm. The filtration column was removed and the liquid at the bottom of the tube was pipetted and the column was placed again. $700 \mu 1$ Buffer W2 (Desalinized Buffer) was added and centrifuged at $15,000 \mathrm{rpm}$ for 30 seconds. The filtration column was removed and the liquid descending to the bottom of the tube was pipetted. After placing the filtration column, $700 \mu 1$ of Buffer W2 was added once more and this time centrifuged at 15,000 rpm for $1 \mathrm{~min}$. The filtration column was removed and the liquid descending to the bottom of the tube was pipetted. The filtration column was then placed again. The tube was once again centrifuged at 15,000 rpm for 1 minute and the filtration column was placed in a $1.5 \mathrm{ml}$ centrifuge tube. $30 \mu \mathrm{l}$ of the solvent which was kept on at $65^{\circ} \mathrm{C}$ for 1 minute was added to the tube. It was then allowed to stand at room temperature for 1 minute and centrifuged at 15,000 rpm for 1 minute. The filtration column was removed and $5 \mu \mathrm{l}$ of the dissolved DNA descending to the bottom of the tube was run on $1 \%$ agarose gel. Their picture was taken and $25 \mu 1$ of dissolved DNA samples were sent for sequencing with the primers.

\section{Statistical Analysis}

Statistical analysis data were analysed with the Statistical Package for the Social Sciences (IBM SPSS Statistic Inc. version 13.0, Chicago, IL, USA). Continuous variables were expressed as mean \pm standard deviation and nominal variables were expressed as frequency and percentage. KolmogorovSmirnov test and Shapiro-Wilk tests of normality were used to identify distribution of variables. Student's t test was used to compare two groups for continuous variables with normal distribution. Chi Square test was used to compare two groups for nominal variables. The statistical significance of the IL-6 genotype between the study and controls and the risk coefficient (OR) were calculated using Pearson's X2 test. Fisher's Exact Test was used for values less than five. Probability $(p)$ values less than 0.05 were considered statistically significant. 


\section{RESULTS}

In the present study, 104 patients were enrolled into each group. The demographic and clinical characteristics of the participants are summarized in Table 1. Significant differences were found in the study group in terms of hyperlipidaemia, smoking, hypertension and diabetes mellitus. In this study, IL-6
-174G/C gene polymorphism has carried out on agarose gel and the results read under UV light (Fig. 1). Allele frequency distributions of IL-6 -174G/C polymorphism in the study and control groups are presented in Table 2. The A allele frequency for IL-6 $-174 \mathrm{G} / \mathrm{C}$ polymorphism was $78.36 \%$ in the control group and $81.25 \%$ in the study group. B allele frequencies were $21.64 \%$ in the control group and

Table 1. Demographic features of the patients

\begin{tabular}{lccc}
\hline & $\begin{array}{c}\text { Study group } \\
(\mathbf{n}=\mathbf{1 0 4})\end{array}$ & $\begin{array}{c}\text { Control group } \\
(\mathbf{n = 1 0 4 )}\end{array}$ & $\boldsymbol{p}$ value \\
\hline Age (years) & $61.11 \pm 11.86$ & $58 \pm 13.35$ & 0.257 \\
Male gender, n (\%) & $74(71.15)$ & $44(42.3)$ & $<\mathbf{0 . 0 0 1}$ \\
Hypertension, n (\%) & $72(69.24)$ & $37(35.58)$ & $<\mathbf{0 . 0 0 1}$ \\
Diabetes mellitus, n (\%) & $36(34.62)$ & $20(19.23)$ & $\mathbf{0 . 0 1 2}$ \\
Smoking, n (\%) & $64(61.53)$ & $43(41.34)$ & $\mathbf{0 . 0 0 4}$ \\
Hyperlipidaemia, n (\%) & $25(24.04)$ & $20(19.23)$ & $\mathbf{0 . 0 3 1}$ \\
\hline
\end{tabular}

$18.75 \%$ in the study group. Although allele B frequency was higher in IL-6 -174G/C polymorphism for patients with coronary artery disease, it was not statistically significant. ( $p=0.464 \mathrm{OR}=0.83 ; 95 \% \mathrm{Cl}$ $=0.51-1.35$ ).

Table 2 presents the risk prediction for the genotype frequency of IL-6 -174G/C polymorphism between the study and control groups. There was no statistically significant result in comparing AA genotype with $\mathrm{AB}$ genotype for IL-6 -174G/C polymorphism $(p=0.257, \mathrm{OR}=0.71 ; 95 \% \mathrm{Cl}=0.39$ 1.28). Similarly, no statistically significant result was observed in comparison with BB genotype. ( $p=0.565$ (Fisher's Exact test $\mathrm{p}$ value), $\mathrm{OR}=1.19 ; 95 \% \mathrm{Cl}=$ $0.25-5.56)$.

\section{DISCUSSION}

Risk factors for coronary artery disease such as

Table 2. Allele and genotype frequency distributions and risk coefficients

\begin{tabular}{ccccc}
$\begin{array}{c}\text { Study group } \\
(\mathrm{n}=104)\end{array}$ & $\begin{array}{c}\text { Control group } \\
(\mathrm{n}=104)\end{array}$ & $x^{*}$ & $p$ value & OR 95\% Cl \\
\hline
\end{tabular}

\begin{tabular}{lccccc}
\hline $\begin{array}{l}\text { Allele } \\
\text { Frequency }\end{array}$ & & & & & \\
A & $169(81.25 \%)$ & $163(78.36 \%)$ & & & \\
\hline B & $39(18.75 \%)$ & $45(21.64 \%)$ & 0.537 & 0.464 & $0.83(0.51-1.35)$ \\
Genotype & & & & \\
Frequency & $69(64.35 \%)$ & $62(59.61 \%)$ & & & \\
\hline AA & $31(29.80 \%)$ & $39(37.50 \%)$ & 1.283 & 0.257 & $0.71(0.39-1.28)$ \\
AB & $4(3.85 \%)$ & $3(2.89 \%)$ & - & 0.565 & $1.19(0.25-5.56)$ \\
\hline BB & & & & & \\
\hline
\end{tabular}

*Fisher's Exact test $p$ value 


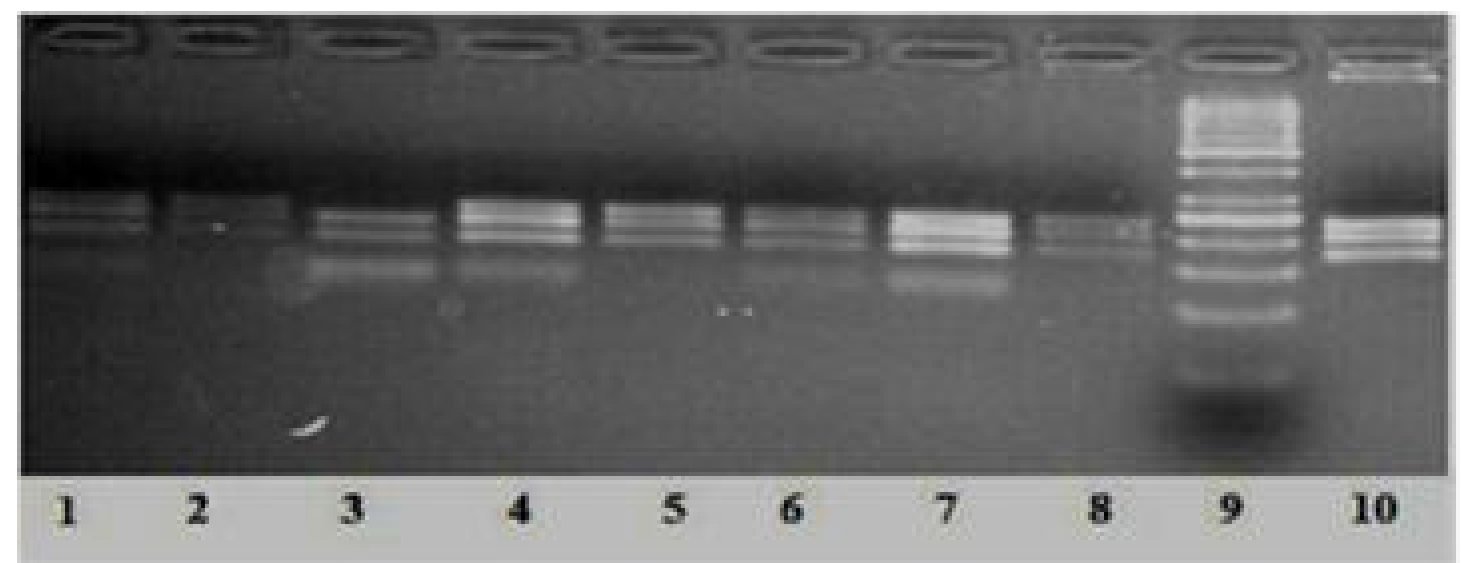

Fig. 1. Cutting results with NlaIII enzyme to determine IL-6 -174G/C change. GG: columns 2,5,8,10 GC: 1,4 columns 6,7 CC: column 3. Column 9 is marker 50 bp fermentas.

age, gender, hyperlipidaemia, diabetes mellitus, hypertension, and active smoking were significantly different in the study group (Table 1). Although all these risk factor's distribution were significantly higher in the study group suggested that two groups were not similar in terms of risk factor, it should be remembered that these risk factors, which have been proven to be associated with severe atherosclerosis, are naturally more in the study group. Due to the association of all these risk factors with inflammation and the other immune mechanisms defined for atherosclerosis, it is considered that evaluation of the inflammatory events underlying atherosclerosis and the regulatory mechanisms, can achieve meaningful results. In atherosclerosis, ordinarily inflammatory cytokines tend to reduce receptor levels, whereas cytokines that stimulate macrophage development and differentiation increase receptor levels. Most T cells in the human atherosclerotic plaque are of the TH1 type, which causes macrophage activation and inflammation [13]. The most important TH1 cytokine is interferon gamma (IFN- $\gamma$ ) which has significant vascular activity. IFN- $\gamma$ stimulates macrophages to increase major macrophage-activating cytokines and phagocytosis and this provides secretion of inflammatory cytokines such as TNF- $\alpha$ and IL-1. This leads to the release of proteolytic enzymes, resulting in the formation of large amounts of toxic oxygen and nitric oxide (NO) radicals [14]. Cytokines such as IL1, IL-6, IL-10, TNF- $\alpha$ were investigated in these studies, where ischemia and reperfusion models were also frequently discussed $[7,15,16]$. Although these inflammatory events show similar characteristics, their individual ethnic or instantaneous different behaviours have increased efforts to reveal genes responsible for their regulation.

Genetic factors play an important role in atherosclerosis, and genome-wide association studies (GWAS) have identified several single nucleotide polymorphisms (SNPs) associated with increased risk of coronary artery disease. The most potent genetic association has been described for SNPs involved in trans regulation of IFN $\gamma$ signalling at locus 9p21 [17]. Many of the identified loci have unknown risk mechanisms, but some are associated with lipoprotein metabolism or atherothrombosis [18].

Recently inflammation and genetics are accepted as two important mechanisms in atherosclerosis and arterial thrombosis. In vitro studies and animal experiments have shown that inflammatory markers are significantly increased in clinically stable angina, unstable angina and acute myocardial infarction [16]. Additionally, these studies support that genetic variation in the inflammatory system increases the risk of coronary artery disease. Differences in genetic regulation may explain why some people do not develop disease but some develop a more severe inflammatory reaction. In a British study of the IL-1 gene, IL-1 gene variants were not significantly associated with the presence or prevalence of the disease, but IL-1Ra 2 homozygotes were associated with single vessel disease [19]. In a cohort study, a statistically significant relationship was found between coronary restenosis and IL-1 gene mutation in patients underwent stenting [20]. IL-6 is another cytokine for which serum levels have been investigated. Serum IL- 
6 levels were also found to be elevated in patients with unstable angina in parallel with CRP and high concentrations of IL-6 were associated with poor prognosis [21]. Atherogenic dyslipidaemia, diabetes as well as insulin resistance during obesity are important in the development of atherosclerosis. TNF$\alpha$ and IL-6 released from adipose tissue independently of atherogenic dyslipidaemia and diabetes have been shown to stimulate the development of inflammation and atherosclerosis [22]. The IL-6 -174G/C gene is a gene site responsible for regulation of this cytokine. C allele was found to decrease plasma IL-6 levels in healthy individuals [23].

The phenotypic reflection of homozygous (CC or $\mathrm{GG}$ ) or heterozygous (GC) genotypes and their effects on diseases have been discussed in some other studies. In a study of familial Mediterranean fever (FMF), it was claimed that high IL-6 production ( $G$ allele transport) may contribute to amyloid development in FMF patients by increasing SAA gene expression [24].

Although various studies have shown that plasma IL-6 concentrations are elevated and thrombopoietin concentrations are decreased in patients diagnosed with thrombocytopenic purpura, studies have not shown the efficacy of IL-6 - 174G/C gene polymorphism [25]. It is known that the release of proinflammatory cytokines such as IL-6 increases during the course of diseases such as FMF, amyloidosis, ITP, thrombosis, sepsis and pulmonary embolism. However, the number of individuals carrying the $-174 \mathrm{G} / \mathrm{C}$ polymorphism, which has been shown to be effective on IL-6 levels, is similar in the study and control groups. This suggests that increasing cytokine release as response to changing environmental conditions during the course of the mentioned diseases may be more important than genetic changes [8, 23-25]. In a study by Losito et al. [23] IL-6 -174G/C gene was suggested to be associated with left ventricular hypertrophy and hypertension in dialysis patients. Vakili et al. [9] reported that this gene polymorphism might be related to acute myocardial infarction and it was suggested that detailed investigation of IL- $6-174 \mathrm{G} / \mathrm{C}$ gene polymorphism would be appropriate in these patients. Ma et al. [10] reported that this gene polymorphism may be effective in ischemic stroke and coronary artery disease. In this study, guided by all these results, we investigated the relationship between coronary atherosclerosis and IL-6 -174G/C gene polymorphism. In this study, IL-6 -174G/C gene polymorphism was carried out on agarose gel and the results were read under UV light. The A allele frequency for IL-6 $174 \mathrm{G} / \mathrm{C}$ polymorphism was $78.36 \%$ in the control group and $81.25 \%$ in the study group. B allele frequency distribution was $21.64 \%$ in the control group and $18.75 \%$ in the study group. Allele B frequency in IL-6 -174G/C polymorphism in the patients with coronary artery disease was higher than the control group, but it was not statistically significant $(p=0.464$ OR $=0.83 ; 95 \% \mathrm{Cl}=0.51-1.35)$. No statistically significant result was found after comparing AA genotype with AB genotype in IL-6 $174 \mathrm{G} / \mathrm{C}$ polymorphism $(p=0.257, \mathrm{OR}=0.71 ; 95 \%$ $\mathrm{Cl}=0.39-1.28)$. No statistically significant result was observed in comparison with BB genotype. $(p=0.565$ (Fisher's Exact test $\mathrm{p}$ value), $\mathrm{OR}=1.19 ; 95 \% \mathrm{Cl}=$ 0.25-5.56) (Table 2).

\section{Limitations}

There are several limitations in our study. Firstly, the sample size was relatively small. Secondly, risk factors for coronary artery diseasewere significantly different in the study group. And we focused on the gene mutations and did not measure plasma IL-6 and C-reactive protein (CRP) levels.

\section{CONCLUSION}

This study demonstrates that; Individuals with $\mathrm{AB}$ genotype do not differ in risk of developing Coronary Artery Disease compared to individuals carrying AA genotype. On the other hand, individuals with $\mathrm{BB}$ genotype had 1.19 times higher risk of developing coronary artery disease than individuals with AA genotype. However, this was not statistically significant. The fact that the allele frequency and genotypic distribution between the groups does not differ statistically suggests that this cytokine's regulation, which is shown to be effective, may be influenced by mechanisms such as environmental, racial and instantaneous organism response other than IL-6 -174G/C gene regulation. Single gene polymorphisms are often not reproducible. Racial and genotypic features may not always produce phenotypic reflections. For this reason, broad-based 
studies should be carried out considering appropriate conditions and multifactorial features.

\section{Conflict of interest}

The author disclosed no conflict of interest during the preparation or publication of this manuscript.

\section{Funding}

This study was supported by Cumhuriyet University Scientific Research Projects (CÜBAP Project No: T-482).

\section{Acknowledgements}

I would like to express my gratitude to Dr.Serdal ARSLAN who provided technical support and assistance in terms of information and methods for DNA isolation and screening of the selected gene region.

\section{REFERENCES}

1. Libby P, Ridker PM, Maseri A. Inflammation and atherosclerosis. Circulation 2002;105:1135-43.

2. Resncik HE, Howard EV. Diabetes and cardiovascular disease. Annu Rev Med 2002;53:245-67.

3. Ridker PM. Clinical application of CRP for cardiovascular disease detection and prevention. Circulation 2003;107:363-9.

4. Christopher KG, Joseph LW. Atherosclerosis: the road ahead. Cell 2001;104:503-16.

5. Borish L, Steinke JW. Cytokines and chemokines. J Allergy Clin Immunol 2003;111:460-75.

6. Heinrich PC, Behrmann I, Haan S, Hermanns HM, MüllerNewen G, Schaper F. Principles of interleukin (IL)-6-type cytokine signalling and its regulation. Biochem J 2003;374(Pt 1):1-20.

7. Kishimoto T. Interleukin-6: discovery of a pleiotropic cytokine. Arthritis Res Ther 2006;8 Suppl 2:S2.

8. Morgan L, Cooper J, Montgomery H, Kitchen N, Humphries SE. The interleukin- 6 gene $-174 \mathrm{G}>\mathrm{C}$ and $-572 \mathrm{G}>\mathrm{C}$ promoter polymorphisms are related to cerebral aneurysms. J Neurol Neurosurg Psychiatry 2006;77:915-7.

9. Vakili H, Ghaderian SMH, Najar RA, Panah AST, Azargashb

E. Genetic polymorphism of interleukin-6 gene and susceptibility to acute myocardial infarction. Coron Artery Dis 2011;22:299305 .

10. Ma Y, Tang RK, Yang X, Peng GG, Liu Y, Wang XM, et al. Lack of an association between interleukin-6 gene promoter polymorphisms $(-174 \mathrm{G} / \mathrm{C},-572 \mathrm{G} / \mathrm{C})$ and ischemic heart disease and/or ischemic stroke: a meta-analysis. Hum Immunol
2011;72:641-51.

11. Liu Y, Berthier-Schaad Y, Fallin MD, Fink NE, Tracy RP, Klag MJ, et al. IL-6 haplotypes, inflammation, and risk for cardiovascular disease in a multiethnic dialysis cohort. J Am Soc Nephrol 2006;17:863-70.

12. Sambrook J, Fritsch EF, Maniatis T. Molecular Cloning: a laboratory manual. 2nd ed. N.Y., Cold Spring Harbor Laboratory, Cold Spring Harbor Laboratory Press, 1989: p. 1659.

13. Gisterå A, Hansson GK. The immunology of atherosclerosis. Nat Rev Nephrol 2017;13:368-80.

14. Uyemura K, Demer LL, Castle SC, Jullien D, Berliner JA, Gately MK, et al. Cross-regulatory roles of interleukin (IL)-12 and IL-10 in atherosclerosis. J Clin Invest 1996;97:2130-8.

15. Kishimoto T. The biology of interleukin-6. Blood 1989;74:110.

16. Tousoulis D, Oikonomou E, Economou EK, Crea F, Kaski JC. Inflammatory cytokines in atherosclerosis: current therapeutic approaches, Eur Heart J 2016;37:1723-32.

17. Harismendy O, Notani D, Song X, Rahim RG, Tanasa B, Heintzman N, et al. 9p21 DNA variants associatedwith coronary arterydisease impair interferon-gammasignalling response. Nature 2011;470:264-8.

18. Lusis AJ. Genetics of atherosclerosis. Trends Genet 2012;28:267-75.

19. Francis SE, Camp NJ, Burton AJ, Dewberry RM, Gunn J, Stephens-Lloyd A, et al. Interleukin 1 receptor antagonist gene polymorphism and coronary artery disease. Circulation 1999;99:861-6.

20. Kastrati A, Koch W, Berger PB, Mehilli J, Stephenson K, Neumann FJ, et al. Protective role against restenosis from an interleukin -1 receptor antagonist gene polymorphism in patients treated with coronary stenting. J Am Coll Cardiol 2000;36216873.

21. Liuzzo G, Biasucci LM, Gallimore JR, Grillo RL, Rebuzzi AG, Pepys MB, et al. The prognostic value of C-reactive protein and serum amyloid A protein in severe unstable angina. $\mathrm{N}$ Engl J Med 1994;331:417-24.

22. Yudkin JS, Stehouwer CD, Emeis JJ, Coppack SW. C reactive protein in healthy subjects: associations with obesity, insulin resistance and endothelial dysfunction: a potential role for cytokines originating from adipose tissue? Atheroscler Thromb Vasc Biol 1999;19:972-8.

23. Losito A, Kalidas K, Santoni S, Jeffery S. Association of interleukin-6 - 174G/C promoter polymorphism with hypertension and left ventricular hypertrophy in dialysis patients. Kidney Int 2003;64:616-22.

24. Yamada T, Okuda Y, Itoh Y. The frequency of serum amyloid A2 alleles in the Japanese population. Amyloid 1998;5:208-11.

25. Foster CB, Zhu S, Erichsen HC, Lehrnbecher T, Hart ES, Choi E, et al. Early Chronic ITP Study Group. Polymorphisms in inflammatory cytokines and Fcgamma in childhood chronic immune thrombocytopenic purpura: a pilot study. Br J Haematol 2001;113:596-99. 